Published in final edited form as:

Methods Enzymol. 2009 ; 453: 417-449. doi:10.1016/S0076-6879(08)04021-4.

\title{
Monitoring Autophagy in Lysosomal Storage Disorders
}

\author{
Nina Raben ${ }^{*}$, Lauren Shea*, Victoria Hill ${ }^{*}$, and Paul Plotz ${ }^{*}$ \\ ${ }^{*}$ The Arthritis and Rheumatism Branch, NIAMS, National Institutes of Health, Bethesda, Maryland, USA
}

\begin{abstract}
Lysosomes are the final destination of the autophagic pathway. It is in the acidic milieu of the lysosomes that autophagic cargo is metabolized and recycled. One would expect that diseases with primary lysosomal defects would be among the first systems in which autophagy would be studied. In reality, this is not the case. Lysosomal storage diseases, a group of more than 60 diverse inherited disorders, have only recently become a focus of autophagic research. Studies of these clinically severe conditions promise not only to clarify pathogenic mechanisms, but also to expand our knowledge of autophagy itself. In this chapter, we will describe the lysosomal storage diseases in which autophagy has been explored, and present the approaches used to evaluate this essential cellular pathway.
\end{abstract}

\section{Introduction}

Lysosomal storage disorders (LSDs) are an extremely diverse group of more than 60 genetic diseases. Individual LSDs are rare disorders, but, as a group, their incidence is estimated to be 1 in 5000-8000 live births (Hodges and Cheng, 2006; Wenger et al., 2003). The majority of LSDs are caused by the deficiency of a single lysosomal hydrolase, leading to the accumulation of the corresponding substrate. LSDs can also result from mutations in proteins involved in the intracellular trafficking of lysosomal enzymes. Two such diseases, mucolipidoses II and III, are caused by a deficiency of the enzyme that catalyzes the addition of mannose-6phosphate (required for lysosomal targeting) to newly synthesized lysosomal hydrolases. Another group of LSDs results from defective transport of the products of lysosomal catabolism across the lysosomal membrane. Examples include cystinosis and sialic acid storage disease. Finally, there are several atypical LSDs, which involve mutations in integral membrane proteins of poorly defined function. These disorders include Niemann-Pick Type $\mathrm{C}$ and juvenile neuronal ceroid lipofuscinosis.

A great deal of progress has been made in the field of LSDs in elucidating genetic defects, developing therapeutic approaches, improving patient care, generating animal models etc. However, the biological pathways from lysosomal storage to cellular dysfunction and death remain largely unknown. In the not so distant past, lysosomes were viewed as simple garbage disposal organelles. Recently, an attractive new view of lysosomes has been proposed by Steven Walkley (Walkley, 2007). According to this view, lysosomes are credited with a prominent role as essential mediators of cellular metabolism. The well-being of lysosomes has broad-reaching effects on many cellular systems, including the multiple vesicular pathways that terminate at these organelles.

One of the pathways destined for the lysosome, macroautophagy (hereafter referred to as autophagy), is a catabolic pathway responsible for the turnover of long-lived cytosolic proteins and organelles, such as mitochondria. Autophagic cargo is sequestered by double-membrane vesicles (autophagosomes) and is ultimately degraded after autophagosome-lysosome fusion. Functional lysosomes are critical for the maturation of autophagosomes and for the degradation of their content. Thus, autophagy seemed an attractive target for studies in LSDs, in which 
lysosomal abnormalities are the primary defects. These studies became possible due to the great progress in, and fascination with, the field of autophagy.

The case for examining autophagy is bolstered by similarities between LSDs, most of which involve severe neurodegeneration, and a number of age-related neurodegenerative diseases, such as Alzheimer's disease, Parkinson's disease, and Huntington's disease. Although the etiology of LSDs is different, namely the accumulation of undegraded compounds in lysosomes, the mechanisms of neurodegeneration may be similar, including the major role of autophagy. Furthermore, inactivation of crucial autophagy genes in mice has been shown to lead to severe neurodegeneration and the accumulation of undegraded polyubiquitinated proteins (Hara et al., 2006; Komatsu et al., 2006). Accumulation of undegraded material may be particularly harmful for post-mitotic cells such as neurons or muscle cells as these cells cannot dilute the accumulated material by cell division.

The precise mechanisms leading to changes in or malfunction of the autophagic pathway in LSDs remain elusive. Furthermore, the link between abnormal autophagy and cell death, in particular neuronal cell death, still needs to be established. It is important to emphasize that the study of autophagy in LSDs is just emerging. The role of autophagy has been investigated in only a handful of LSDs, but the approach is certain to be extended to a broader range of LSDs in the near future.

The LSDs in which autophagy has been studied to date include Multiple Sulfatase Deficiency (MSD), Mucopolysaccharidosis Type IIIA (MPS IIIA), $\mathrm{G}_{\mathrm{M} 1}$-Gangliosidosis, Pompe Disease (PD), Niemann-Pick Disease Type C (NPC), Neuronal Ceriod Lipofuscinosis (NCL),

Mucolipidosis Type IV, and Danon Disease. A variety of available methods have been adapted to monitor autophagy in LSDs, which now compose an arsenal of general techniques. We will first describe these general techniques, providing references for their application to LSDs. We will then focus on the diseases themselves and highlight some of the less commonly used methods (referred to as specific techniques) employed to study them.

\section{General Techniques to Monitor Autophagy in LSDs}

\subsection{Lysosomes and associated vesicular pathways}

2.1.1. Vesicular markers-Several membrane proteins are particularly useful in the study of vesicle morphology and distribution. Microtubule-associated protein 1 light chain 3 (LC3) exists in the cytoplasm as a soluble form (LC3-I). A phosphatidylethanolamine (PE)conjugated form of LC3 (LC3-II) is associated with the phagophore and the inner autophagosomal membrane and is a highly specific marker for these structures (Kabeya et al., 2000). Upon fusion with the lysosome, LC3-II on the inner autophagosomal membrane is degraded (Xie and Klionsky, 2007). LC3-I and II can be distinguished based on their migration in an SDS-PAGE gel (see the chapter by Kimura et al, in this volume). The LC3-II:LC3-I ratio, as determined by western blotting, is a commonly used measure of autophagosome levels (Cao et al., 2006; Koike et al., 2005). Recently it has been noted that a more accurate standardization may be achieved by comparing LC3-II levels to other internal controls (Klionsky et al., 2008; Liao et al., 2007; Settembre et al., 2008a). Staining cells or tissues with anti-LC3 antibodies indicates the steady state level of autophagosomes. Additional methods include transfection of diseased cells with GFP-LC3 (Cao et al., 2006; Gonzalez-Polo et al., 2005), as well as generation of GFP-LC3 transgenic mice on an LSD background (Koike $e t$ al., 2005) (also see the chapter by N. Mizushima in volume 452).

Other vesicular markers have also proven useful in studying LSD pathology. Cathepsins are lysosomal proteases that can serve as markers for the lysosomal lumen (Tanaka et al., 2000), and LAMP-1 and LAMP-2 are transmembrane proteins localized specifically to lysosomal 
membranes. Double labeling with LAMP-1 and LC3 antibodies has been used in fibroblasts (Raben et al., 2003; Settembre et al., 2008a) and brain (Koike et al., 2005) to quantify autolysosomes as a surrogate measure of the efficiency of autophagosome/lysosome fusion. Late endosomes stain positive for both LAMP-1 and the cation-independent mannose-6phosphate receptor (CI-MPR), whereas early endosomes are marked by both rab5 and early endosome antigen 1 (EEA1) (Fukuda et al., 2006b). Structural information obtained with these markers complements functional studies of endocytosis (see subsequently).

As an alternative to immunological methods, autophagosomes have been visualized with the autofluorescent drug monodansylcadaverine (MDC). Cells are incubated with MDC and examined via fluorescence microscopy (Jennings et al., 2006) (also see the chapter by Vázquez and Colombo in volume 452). In addition, MDC-labeled cells can be lysed, and a solution of ethidium bromide added to the lysate to normalize for cell number by measuring DNA fluorescence (Pacheco et al., 2007). Concerns have been raised, however, that MDC is not completely specific for autophagosomes; this technique is thus best employed in combination with other methods of autophagosome detection (Klionsky et al., 2008).

LysoTracker is a fluorescent dye that preferentially accumulates in vesicles with an acidic $\mathrm{pH}$. LysoTracker staining can be used to detect abnormalities in vesicular $\mathrm{pH}$ (Eskelinen et al., 2004) and to examine the efficiency of autophagosome/lysosome fusion in live cells (GonzalezPolo et al., 2005). It is important to note that as a weakly basic amine, LysoTracker may cause lysosome alkalinization. Thus, in studies of live cells, images should be taken shortly after staining to reduce this effect. LysoTracker-stained cells can also be fixed in paraformaldehyde followed by mounting in Vectashield mounting medium without significant loss of fluorescent signal (Cao et al., 2006).

2.1.2. Electron microscopy (EM)—Autophagosomes are typically identified with EM by the presence of a double membrane, and are often classified as AVi (immature vesicles, containing undegraded cellular material) and $\mathrm{AVd}$ (mature vesicles, containing partially degraded identifiable cellular material) (Eskelinen et al., 2002, 2004; Koike et al., 2005; Tanaka et al., 2000). This classification has recently drawn criticism, however, as autophagosome maturation is now seen as a gradual process characterized by numerous intermediate states (Klionsky et al., 2008) (also see the chapter by Ylä-Anttila and Eskelinen in volume 452). Morphometric analysis offers a quantitative interpretation of EM images. With this technique, several EM image frames are scored for the number of various vesicular structures present (double membrane, multivesicular, multilamellar, and multidense bodies were categories used in one study of neuronal ceroid lipofuscinosis (Cao et al., 2006)). The combination of EM and immunogold labeling can facilitate identification of vesicles that are difficult to distinguish in conventional EM. In a mouse model of Pompe disease, for example, this technique was used to characterize non-contractile inclusions in muscle as LAMP-1positive (Fukuda et al., 2006b).

2.1.3. Subcellular fractionation-Many of the techniques described previously can also be applied to subcellular fractions isolated from tissues, allowing for more specific and detailed analysis of autophagosomes and other vesicle types (for example, see the chapter by Kaushik and Cuervo in volume 452). In studying LSDs, fractionation has been performed on brain (Liao et al., 2007) and liver (Cao et al., 2006) samples from mice, as well as on cultured fibroblasts (Eskelinen et al., 2004).

1. Mouse brains from wild-type and $\mathrm{Npc}^{-/-}$(a model of Niemann-Pick type $\mathrm{C}$ disease) mice are dissected in ice-cold artificial cerebrospinal fluid $(124 \mathrm{mM} \mathrm{NaCl}, 3 \mathrm{mM} \mathrm{KCl}$, $1.25 \mathrm{~m} M \mathrm{KH}_{2} \mathrm{PO}_{4}, 3.4 \mathrm{~m} M \mathrm{CaCl}_{2}, 2.5 \mathrm{~m} M \mathrm{MgSO}_{4}, 26 \mathrm{~m} M \mathrm{NaHCO}_{3}, 10 \mathrm{~m} M \mathrm{D}-$ glucose (Kramar et al., 2004)), followed by homogenization in buffer containing 3 
$\mathrm{mmol} / \mathrm{L}$ imidazole, $250 \mathrm{mmol} / \mathrm{L}$ sucrose, $1 \mathrm{mmol} / \mathrm{L}$ EDTA, $\mathrm{pH} 7.4$, and protease inhibitors (Sigma, St. Louis, MO).

2. Homogenates are centrifuged for $10 \mathrm{~min}$ at $1500 \times \mathrm{g}$.

3. The sucrose concentration of the supernatant fraction (postnuclear lysates) is adjusted to $40.6 \%$ by the slow addition of $62 \%$ sucrose in homogenization buffer-EDTA. The supernatant is then overloaded with $35 \%$ and $25 \%$ sucrose in the same buffer, and the samples are centrifuged in an SW 55 rotor (Beckman Instruments, Palo Alto, CA) at $14,000 \times g$ for $90 \mathrm{~min}$ at $4{ }^{\circ} \mathrm{C}$.

4. Following centrifugation, 3 fractions are collected: a late-endosome/lysosome enriched fraction (25\% sucrose), an early endosomes-enriched fraction (25\%-35\% sucrose) and a fraction enriched in plasma membranes (35\%-40.6\% sucrose). The distribution of particular proteins in these fractions is then determined by western blotting (Liao et al., 2007). The details of the fractionation protocol can be found in de Araujo et al., (2006).

Liver: Cellular fractionation and isolation of autophagic vacuoles have been performed in livers from a mouse model of Juvenile Neuronal Ceroid Lipofuscinosis (Cao et al., 2006). The isolation protocol is a modification ( $\mathrm{Yu}$ et al., 2005) of the original method described by Marzella et al., (1982). Briefly, the procedure involves the following steps:

1. Mice are starved for $12 \mathrm{~h}$ and injected intraperitoneally with $5 \mathrm{mg} / 100 \mathrm{~g}$ of body weight of vinblastine in normal saline $(0.9 \% \mathrm{NaCl}) 3 \mathrm{~h}$ before sacrificing.

2. Livers are harvested (livers from 4 mice are pooled), homogenized (in $0.25 M$ sucrose $(1: 2 \mathrm{wt} / \mathrm{vol}))$, and separated by differential centrifugation to produce a low-speed pellet containing the nuclear fraction and unbroken cells, and a high-speed pellet that is enriched in AVs, lysosomes, and mitochondria.

3. A discontinuous metrizamide gradient is then used to separate the lysosomal fraction, two AV fractions (light AV fraction and heavy AV fraction), and the mitochondrial fraction. Fractions are collected and examined by Western blotting and EM (Cao et al., 2006).

Fibroblasts: Subcellular fractionation has been performed in mouse embryonic fibroblasts obtained from LAMP-1 and LAMP-2 double-deficient mice (Eskelinen et al., 2004). In this case, the lysosome-enriched Percoll gradient fraction is isolated and analyzed with lysosomal markers.

2.1.4. Pharmacological modulation-Pharmacological agents have been used to determine the functional capacity of autophagy in LSDs. Bafilomycin, for example, blocks autophagosome/lysosome fusion by causing lysosomal alkalinization. If bafilomycin-treated cells accumulate more LC3-II than untreated cells, this indicates that autophagosome turnover through fusion with lysosomes is occurring to some extent (Settembre et al., 2008a). Similarly, LC3-II accumulation in response to treatment with lysosomal protease inhibitors such as E64 and pepstatin relative to the untreated control indicates that any block in autophagy is not complete (Pacheco et al., 2007) (see the chapter by Kimura et al., in volume 452).

2.1.5. Pathway analysis-Pathway analysis has been used to determine whether an observed increase in the number of autophagosomes is due to an induction of autophagy. The Akt/mTOR pathway, downstream of class I PI3K, and the ERK pathway are known to regulate autophagic activity (Corcelle et al., 2006; Lum et al., 2005; Tassa et al., 2003). Class I PI3Kindependent regulation of autophagy has also been observed; in this case, the class III PI3K- 
interacting protein Beclin 1 appears to play a major role (Tassa et al., 2003). Western blot quantification of the levels of these proteins has been used in LSDs where abnormal autophagic activity is observed (Cao et al., 2006; Pacheco et al., 2007; Takamura et al., 2008).

2.1.6. Vesicular $\mathrm{pH}$ and endocytic trafficking-Several techniques are available for measuring late endosomal/lysosomal $\mathrm{pH}$, which is another key parameter of vesicular functionality.

i. The assay we utilize in our lab (to measure the lysosomal $\mathrm{pH}$ in myoblasts derived from Pompe mice) is based on measuring the ratio of $\mathrm{pH}$-sensitive ORG488 (Oregon Green) or FL (fluorescein) to $\mathrm{pH}$-insensitive TMR (tetramethylrhodamine) fluorescence emissions (Fukuda et al., 2006b).

Procedure:

1. Myoblasts are grown in Dulbecco's modified Eagle's medium (DMEM) supplemented with $20 \%$ fetal calf serum, $10 \%$ horse serum, $1 \%$ chick embryo extract, $100 \mathrm{IU} / \mathrm{ml}$ penicillin, and $100 \mu \mathrm{g}$ of streptomycin (Invitrogen, Carlsbad, CA).

2. Cells are split $24 \mathrm{~h}$ before the experiments on collagen-coated $(0.4 \%)$ or poly-D-Lysine chamber slides [Lab-Tek ${ }^{\circledR}$ Chamber Slide ${ }^{\text {TM }}$ System, Nunc, Naperville, IL, Cat. No. 154941 ( 8 well glass slide)] at low density $\left(2.0 \times 10^{3}\right.$ cells $\left./ \mathrm{cm}^{2}\right)$.

3. Myoblasts are incubated with either a mixture of ORG488 (dextran, Oregon Green ${ }^{\circledR} 488$; Cat. No. D7170) and TMR-conjugated dextrans (which allows $\mathrm{pH}$ detection in a range from 4.0 to 5.5 ; Cat. No. D1868) $(1 \mathrm{mg} / \mathrm{ml}$ each) or FL/TMR-double conjugated dextran (for pH 4.8-6.0) (2 mg/ml) (Cat. No. D1950) (all from Molecular Probes/Invitrogen) for $24 \mathrm{~h}$.

4. Cells are washed and incubated in dextran-free complete medium (chase) for 2 and $36 \mathrm{~h}$.

5. Confocal images of cells in serum-free DMEM (Biosource, Rockville, MD) are recorded using the appropriate emission ranges.

6. The FL/ORG488 over TMR ratio of individual dextran-containing vesicles is used to determine lysosomal $\mathrm{pH}$; TMR acts as an internal control for dye uptake (Maxfield 1989). The calculated ratio is then converted to a $\mathrm{pH}$ value by using a calibration curve, which is generated by treating the dextran labeled cells with $1 \mathrm{~m} M$ monensin (Cat. No. M5273) and $1 \mathrm{~m} M$ nigericin (Cat. No. N7143) (both from Sigma) for $5 \mathrm{~min}$ in buffers of $\mathrm{pH} 4.8$ to 6.0 in increments of $0.1-0.2 \mathrm{pH}$ units. Monensin and nigericin are ionophores that neutralize the acidic interior of endosomes/lysosomes without affecting the membrane potential. Acetate buffer $(25 \mathrm{mM})$ is used for $\mathrm{pH} 4.8$ to 5.7 , and MES [2-(N-morpholino)ethanesulfonic acid] buffer $(25 \mathrm{mM})$ is used for $\mathrm{pH}$ 5.7 to 6.0. Both buffer solutions contain $5 \mathrm{mM} \mathrm{NaCl}, 115 \mathrm{mM} \mathrm{KCl}$, and 1.2 $\mathrm{mM} \mathrm{MgSO}_{4}$

ii. Acridine orange (AO) (solution in water) (Molecular Probes/Invitrogen, Cat. No. A3568), a fluorescent weak base that accumulates in acidic compartments, can be used to visualize lysosomes and to evaluate gross abnormalities in lysosomal $\mathrm{pH}$. Upon entering acidic compartments such as lysosomes, AO becomes protonated and sequestered; $\mathrm{AO}$ shows red fluorescence in an acidic environment and green fluorescence in a neutral environment. 
We use AO to demonstrate the presence of large alkalinized lysosomes in cultured myotubes from Pompe mice: the cells are loaded with AO $(2.5 \mu \mathrm{g} / \mathrm{ml})$ in DMEM medium for $10 \mathrm{~min}$ at $37^{\circ} \mathrm{C}$ and analyzed by confocal microscopy (our unpublished data).

AO can also be used to demonstrate a higher than normal acidic environment of lysosomes, as shown in fibroblasts derived from patients with Mucolipidosis type IV (Soyombo et al., 2006). In this case, the cells are incubated with AO (1 $\mu M$ for 10 $\mathrm{min}$ ) in the standard bath solution, containing $140 \mathrm{~m} M \mathrm{NaCl}, 5 \mathrm{~m} M \mathrm{KCl}, 1 \mathrm{~m} M$ $\mathrm{CaCl}_{2}, 1 \mathrm{mM} \mathrm{MgCl}_{2} 10 \mathrm{~m} M$ Hepes, $\mathrm{pH} 7$.4. Increased $\mathrm{AO}$ accumulation in the lysosomes resulting in a brighter $\mathrm{AO}$ fluorescence indicates that the lysosomes in the diseased cells are over-acidified (Soyombo et al., 2006).

iii. To evaluate the $\mathrm{pH}$ of enlarged lysosomes in myotubes derived from Pompe mice we have also used two LysoSensors: DND-189 ( $\mathrm{pKa}=5.2)($ Cat. No. L-7535), which fluoresces in an acidic environment $(\mathrm{pH} \leq 5.2)$, and DND-153 ( $\mathrm{pKa}=7.5)$ (Cat. No. $\mathrm{L}-7534)$, which fluoresces in both an acidic and in a neutral environment $(\mathrm{pH} \leq 7.5)$ (both LysoSensors are from Molecular Probes). The cells are incubated with DND-153 or DND-189 (in DMEM medium) at $1 \mu M$ for 60 minutes, washed several times with medium and analyzed by confocal microscopy.

iv. DAMP (N-(3-((2,4-dinitrophenyl)amino) propyl)-N-(3-aminopropyl) methylamine), a nonfluorescent, weakly basic amine that traffics to acidic organelles, can be visualized by staining with anti-dinitrophenol antibodies. This approach, developed by Anderson and Orci (1988) has been used to study vesicular pH in LAMP-2deficient mice (Tanaka et al., 2000) and in LAMP-1/LAMP-2-deficient fibroblasts (Eskelinen et al., 2004).

To monitor endocytic trafficking to lysosomes, labeled dextran, a fluid-phase endocytic marker, can be used in combination with LysoTracker Red. This approach has been used, for example, in studying autophagy in a mouse model of Juvenile Neuronal Ceroid Lipofuscinosis (JNCL) (Cao et al., 2006; Fossale et al., 2004).

Procedure (Fossale et al., 2004):

1. Neuron-derived JNCL cells are seeded at a density of 3-5 $\times 10^{4}$ cells/well in 4-well chamber slides and grown overnight at $33{ }^{\circ} \mathrm{C}$.

2. Growth medium (DMEM, Gibco BRL) supplemented with $10 \%$ fetal bovine serum and $24 \mathrm{mM} \mathrm{KCl}$ is exchanged for fresh, pre-warmed medium containing $500 \mathrm{n} M$ LysoTracker Red DND-99 (Cat. No. L-7528) or $1 \mathrm{mg} / \mathrm{ml}$ dextran-FITC (Cat. No.D-7178) (both from Molecular Probes/Invitrogen).

3. Cells are incubated at $33^{\circ} \mathrm{C}$ for $45 \mathrm{~min}$ with LysoTracker or for $15 \mathrm{~min}$ with labeled dextran.

4. Cells are then placed on ice, washed for $10 \mathrm{~min}$ in ice-cold dye-free medium, and fixed with $4 \%$ formaldehyde in PBS for 20 min on ice.

5. Slides are prepared with Vectashield mounting medium (Cat. No. H-1000; Vector Laboratories; Burlingame, CA), and cells are analyzed by confocal microscopy.

\subsection{Consequences of Impaired Autophagy in LSDs}

2.2.1. Protein turnover-Turnover of long-lived proteins, known substrates of autophagy, has been quantified in a radio-labeled amino acid release assay (Pacheco et al., 2007; Tanaka et al., 2000) (also see the chapter by Bauvy et al., in this volume). In a variation on this procedure, cells are treated with ammonium chloride $(20 \mathrm{mM})$ and leupeptin $(0.1 \mathrm{mM})$ to inhibit 
all lysosomal proteolysis, allowing evaluation of the contribution of lysosomal pathways. Similarly, treating cells with the macroautophagy inhibitor 3-methyladenine (3-MA, $10 \mathrm{mM}$ ) reveals the contribution of macroautophagic proteolysis. Subtracting the macroautophagic proteolysis from the lysosomal proteolysis yields the contribution of nonmacroautophagic lysosomal pathways (chaperone-mediated autophagy and microautophagy). In these experiments, proteolysis measurements are initiated $1 \mathrm{~h}$ after the inhibitors are added and are continued for only 3 additional hours, to avoid possible side effects from lengthy inhibitor treatment (Eskelinen et al., 2004).

2.2.2. Ubiquitinated proteins-Autophagy plays a major role in the degradation of ubiquitinated proteins (Hara et al., 2006; Komatsu et al., 2005, 2006). Western blotting of tissue lysates and subcellular fractions with anti-ubiquitin antibodies reveals defects in autophagic removal of ubiquitinated substrates in several LSDs (Liao et al., 2007; Settembre et al., 2008a). Accumulation of p62/SQSTM1, a protein that binds both ubiquitinated substrates and LC3 (Pankiv et al., 2007), is an indicator of defective autophagy (Settembre et al., 2008a).

2.2.3. Cell viability - In vitro models of LSDs are particularly well suited for cell viability assays. Multiple methods are available to assess cell viability. For example, viability can be measured using the vital dye, propidium iodide (PI; Sigma, Cat. No. P4170), which is added to cultured cells at a concentration of $1 \mu \mathrm{g} / \mathrm{ml}$. The cells are then incubated for 10-15 min at room temperature (protected from light), washed and examined by fluorescence microscopy or flow cytometry (PI is excluded from viable cells) (Gonzalez-Polo et al., 2005). Cell viability in a cerebellar cell model of juvenile neuronal ceroid lipofuscinosis was measured using the Cell-Titer-96 AQueous Non-Radioactive Cell Proliferation Assay (Promega, Cat. No.G5421), according to the manufacturer's specifications (Cao et al., 2006; Fossale et al., 2004).

The viability of wild-type and LSD cells can be measured after induction of autophagy by starvation (Gonzalez-Polo et al., 2005) or by oxidative stress following the addition of varying concentrations of hydrogen peroxide as a stressor (Fossale et al., 2004). The effects of autophagic inhibitors (3-MA) and stimulators (rapamycin) on cell survival can be examined (Cao et al., 2006). These compounds may also be administered in combination with a stressinducing agent (for example, paraquat for oxidative stress (Takamura et al., 2008)) to further elucidate the role of autophagy in LSD pathology.

\subsection{Mitochondrial Abnormalities}

The mitochondrial-lysosomal axis theory of aging postulates that oxidized material accumulates in lysosomes as cells age, which results in decreased degradative capacity of lysosomes (Terman and Brunk 2006). The autophagic/lysosomal pathway is the major route of destruction for damaged mitochondria (potent generators of reactive oxygen species); therefore, mitochondria accumulate and subject cells to increasing oxidative stress when autophagy is dysfunctional. Investigating the condition of mitochondria is thus highly relevant in LSDs where autophagy may be impaired (Kiselyov et al., 2007).

2.3.1. Mitochondrial markers-Mitochondria can be visualized with antibodies against grp75, a chaperone protein that localizes to the inner mitochondrial membrane (Fossale $e t$ al., 2004), as well as with the fluorescent dye 123 rhodamine (Jennings, Jr. et al., 2006). Immunostaining with grp75 antibody is performed on fixed cells, whereas fluorescence experiments are done on live cells, and in both cases the standard procedures can be followed. MitoTracker Red is also used in studies of LSDs (Takamura et al., 2008). This compound offers the advantage of being retained in mitochondria even after membrane potential is lost during fixation, although initial labeling does require intact membrane potential (Poot et al., 
1996). Several probes, such as MitoTracker Red CMXRos or MitoTracker JC-1 (Molecular Probes) can be used for mitochondrial labeling of cells according to standard techniques (Takamura et al., 2008).

EM and transfection with the mitochondrial marker mt-DsRed may also be employed to visualize mitochondria (Fossale et al., 2004; Gonzalez-Polo et al., 2005; Settembre et al., 2008a). Mitochondrial fragmentation is observed in LSD models (Jennings, Jr. et al., 2006; Takamura et al., 2008). Cytochrome $c$ oxidase subunit IV (cox4) is an abundant protein in mitochondria, and Western blotting for $\operatorname{cox} 4$ can be used to detect mitochondrial aberrations (Settembre et al., 2008a).

2.3.2. Membrane potential-To assess the functional condition of mitochondria, the mitochondria-specific, voltage-dependent dye $\mathrm{DiOC}_{6}$ can be employed. This positively charged fluorescent probe accumulates only in mitochondria with a strongly negative membrane potential. The approach has been used, for example, to demonstrate the presence of dysfunctional mitochondria in Multiple Sulfatase Deficiency (MDS); the experiments have been done in vitro, in mouse embryonic fibroblasts (MEFs) derived from wild type and MDS mice (Settembre et al., 2008a). The procedure includes treatment of PBS-washed cells with $\mathrm{DiOC}_{6}$ dye (Sigma; $40 \mathrm{n} M$ ) and $1 \mu \mathrm{g} / \mathrm{ml}$ propidium iodine for $15 \mathrm{~min}$ at $37^{\circ} \mathrm{C}$ followed by flow cytometry, which identifies the percentage of cells in which mitochondrial membrane potential has been lost (Gonzalez-Polo et al., 2005; Settembre et al., 2008a). MitoTracker JC-1, another probe that accumulates in mitochondria, is also used to measure mitochondrial membrane potential. The procedure involves incubation of cultured cells with the MitoTracker probe followed by imaging using confocal microscopy: for example, primary cultured astrocytes from $\beta$-galactosidase knockout mice (a model of $\mathrm{G}_{\mathrm{M} 1}$-gangliosidosis) grown on coverslips in Hanks' balanced solution were loaded with $3 \mu M$ MitoTracker JC-1 (Molecular Probes) for 20 $\min$ at $37^{\circ} \mathrm{C}$. In mitochondria with weak membrane potential, JC-1 monomers give off green fluorescence. In mitochondria with high membrane potential, however, the probe accumulates and forms aggregates that give off red fluorescence (Takamura et al., 2008).

2.3.3. ATP synthase subunit $c$ accumulation-Autophagy is the major cellular pathway responsible for recycling aging mitochondria. Thus, it is expected that mitochondrial proteins will accumulate in autophagy-deficient cells. Accumulation of the mitochondrial ATP synthase subunit $c$ has been detected by Western blotting and/or immunostaining in patients' samples and in animal models in several LSDs (Cao et al., 2006; Elleder et al., 1997; Koike et al., 2005). Both immunoblot and immunostaining are performed according to standard procedures.

\section{LSDs Analyzed for Autophagic Involvement}

\subsection{Lysosomal Hydrolase Deficiencies}

3.1.1. Multiple sulfatase deficiency (MSD) and mucopolysaccharidosis Type IIIA (MPSIIIA, Sanfilippo A)-Multiple sulfatase deficiency (MSD) is caused by defects in sulfatase modifying factor 1 (SUMF1), the only enzyme responsible for an essential posttranslational modification of sulfatases (Cosma et al., 2003; Dierks et al., 2003). The deficiency results in a profound reduction in the activity of all sulfatases, leading to massive lysosomal storage of sulfated glycosaminoglycans and sulfolipids (Hopwood and Ballabio, 2001). Deficiencies of individual sulfatases cause six separate lysosomal storage diseases (LSDs), including MPS IIIA [sulfamidase (Heparan N-sulfatase) deficiency]. The phenotype of MSD patients combines all features observed in individual sulfatase deficiencies, including progressive neurodegeneration, developmental delay, visceromegaly, and skeletal involvement. 
Model systems: Sumf1 knockout (KO) mice were developed as an animal model of MSD (Settembre et al., 2007). Two natural murine models are available for MPSIIIA (Bhattacharyya et al., 2001; Bhaumik et al., 1999). Mouse embryonic fibroblasts (MEF) have been derived from both MSD and MPSIIIA mice and embryonic liver macrophages (ELM) from the MSD model. Both cell types demonstrate lysosomal storage pathology (Settembre et al., 2008a,b).

General techniques: Several general techniques have been applied to detect an increase in the number of autophagosomes in vivo, specifically in the brains of MSD mice (Settembre et al., 2008a,b). Immunoblotting and immunofluorescence reveal elevated LC3-II levels and an increased number of LC3-positive vesicles in brain. EM shows abundant early/immature autophagic vacuoles in cerebellum and cerebral cortex sections, suggesting a defect in autophagosome maturation. The development of adequate tissue culture models, MEFs and ELMs derived from MSD mice, facilitates analysis of the autophagic defect. Reduced colocalization of LAMP-1 and LC3, observed by confocal microscopy in starved and non-starved MEFs, is an indication that a block in autophagosomal-lysosomal fusion, rather than induction of autophagy, may be responsible for the increased number of autophagosomes. The in vitro system also makes possible assessment of the degree of the autophagic block: treatment of MEFs with bafilomycin $A_{1}$, a known inhibitor of autophagosomal-lysosomal fusion or lysosomal hydrolase activity, increases LC3-II levels. This finding indicates that the defect in fusion is partial rather than complete (Settembre et al., 2008a,b).

Specific techniques: The functional consequences of the autophagic block in MSD and MPSIIIA are analyzed by several approaches (Settembre et al., 2008a,b).

a. The ability of MEFs and ELMs to degrade exogenous substrates of autophagy was tested. Mutant huntingtin (involved in Huntington disease) and alpha-synuclein (involved in familial Parkinson's disease) are two such substrates. Mutant Gln74Q74 huntingtin (which encodes the first exon of huntingtin with 74 glutamine repeats) or A53T alpha-synuclein were fused with GFP and transiently expressed in MEFs and ELMs. The increased accumulation of GFP-fused mutant proteins in MSD cells was examined by western blot analysis with anti-GFP antibody, and an increase in the number of GFP-Q74 aggregates was monitored by immunofluorescence.

b. The accumulation of endogenous substrates, such as ubiquitinated proteins, p62/ SQSTM1, and mitochondria was monitored. Immunohistochemical staining, immunofluoresence, and western analyses were used to demonstrate the progressive age-dependent accumulation of ubiquitin-positive inclusions in the cerebral cortex and other regions of the MSD brain. Double-staining with NeuN, a neuronal marker, was used to show that these inclusions are located in MDS neurons.

Immunofluorescence with anti-ubiquitin and anti-p62/SQSTM1 antibodies showed significant colocalization of $\mathrm{p} 62 / \mathrm{SQSTM} 1$ with polyubiquitinated proteins in the diseased brain.

c. Mitochondrial number and function were analyzed. EM of brain sections and MEFs as well as immunoblotting with anti-cox4 demonstrated an increased number of mitochondria. A significant reduction in mitochondrial membrane potential in MSD, measured by using a mitochondria specific voltage-dependent dye $\left(\mathrm{DiOC}_{6}\right)$ was observed in both the normal and starved condition.

Thus, lysosomal dysfunction in MSD and MPSIIIA is associated with impairment in autophagososmal-lysosomal fusion and a consequent block in autophagy. The reduced capacity of lysosomes to degrade the autophagic cargo results in accumulation of damaged mitochondria and polyubiquitinated protein aggregates, the putative mediators of neuronal cell death in these two disorders and possibly in other LSDs (Settembre et al., 2008a). 
3.1.2. $\mathbf{G}_{\mathbf{M} 1}$-gangliosidosis $-\mathrm{G}_{\mathrm{M} 1}$-gangliosidosis (Norman-Landing Disease) is caused by a deficiency of the lysosomal enzyme acid beta-galactosidase-1 ( $\beta$-gal), which hydrolyzes the terminal beta-galactosidic residue from $\mathrm{G}_{\mathrm{M} 1}$ ganglioside and other glycoconjugates. The deficiency results in the generalized accumulation of $\mathrm{G}_{\mathrm{M} 1}$ ganglioside and other enzyme substrates, including glycolipid $\mathrm{G}_{\mathrm{A} 1}$, oligosaccharides, and intermediates of keratan sulfate degradation. The clinical manifestations of $\mathrm{G}_{\mathrm{M} 1}$-gangliosidosis include visceromegaly, skeletal dysplasias, and severe progressive central nervous system damage. A deficiency in the same beta-galactosidase is also the primary defect in mucopolysaccharidosis type IVB (MPSIVB, Morquio disease), in which keratan sulfate is the predominant storage material. No neurological involvement is seen in MPSIVB.

The data on autophagy in $\mathrm{G}_{\mathrm{M} 1}$-Gangliosidosis have been presented in one publication so far (Takamura et al., 2008).

Model systems: A knockout mouse model with the neurological phenotype of human $\mathrm{G}_{\mathrm{M} 1^{-}}$ gangliosidosis is available (Itoh et al., 2001; Matsuda et al., 1997). Primary culture of astrocytes from the murine model has also been utilized.

General techniques: Several general methods were used to demonstrate the increase in autophagy in $\mathrm{G}_{\mathrm{M} 1}$-gangliosidosis (Takamura et al., 2008). Immunoblotting and immunoflourescence revealed an increase in the LC3-II level in brains of $\beta-\mathrm{gal}^{-/-}$mice, particularly in the sites of neuronal death, the cerebellum and brain stem. Immunofluorescence also revealed the colocalization of LC3 and $\mathrm{G}_{\mathrm{M} 1}$ ganglioside. Induction of autophagy was associated with increased expression of Beclin 1 in both brain lysates and cultured astrocytes from beta-gal ${ }^{-/-}$mice.

Specific techniques: A number of specific methods were used to address the question of mitochondrial involvement.

a. Measurement of cytochrome $c$ oxidase activity in brains from $\beta$-gal ${ }^{-/-}$mice revealed decreasing mitochondrial functionality, paralleling disease progression.

Mitochondrial isolation kit and mitochondrial activity kit (both from BioChain Institute, Inc., Hayward, CA USA) are used to isolate mitochondria from the mouse brain and cultured astrocytes and to determine the activity of cytochrome $c$ oxidase

(Takamura et al., 2008). Confocal microscopy and mitochondrial membrane potential measurement with MitoTracker JC-1 staining showed abnormally small fragmented or circulated mitochondria with a reduced membrane potential in beta-gal ${ }^{-/-}$primary astrocytes.

b. The functional relevance of the observed mitochondrial dysfunction to cell death was addressed by subjecting primary astrocytes to oxidative stress (the cells were cultured with $250 \mu M$ paraquat (Cat. No. 160-08871; Wako Pure Chemical Industries, Ltd, Tokyo, Japan) for $24 \mathrm{~h}$. Beta-gal ${ }^{-/-}$astrocytes die at an increased rate compared to wild-type cells as shown by lactate dehydrogenase (LDH) cytotoxicity assay. LDH is a soluble cytosolic enzyme that is released into the culture medium if the integrity of the cellular membrane is lost. LDH activity (LDH Cytotoxicity Assay Kit; Cayman Chemical, Ann Arbor, MI, Cat. No. 10008882) in the medium can be used for evaluation of cytotoxicity caused by chemical compounds. Addition of ATP and 3$\mathrm{MA}$, inhibitors of autophagy, to paraquat treated $\beta$ - $\mathrm{gal}^{-/-}$astrocytes results in decreased cell death. The addition of rapamycin, an inducer of autophagy, has no effect on cell survival.

Thus, in $\mathrm{G}_{\mathrm{M} 1}$-gangliosidosis there is evidence of mitochondrial abnormalities and activation of autophagy, both being age-dependent, and paralleling the degree of neurodegeneration. 
3.1.3. Pompe disease (PD)-Pompe disease (Glycogen Storage Disease type II) is caused by a deficiency of acid alpha-glucosidase (GAA), the enzyme responsible for degradation of glycogen to glucose in the lysosome. Lysosomal retention of glycogen occurs in all tissues. Unlike many other LSDs, PD is not known to be a neurodegenerative disease, and the major pathology is observed in cardiac and skeletal muscle. In the most severe cases, any possible neurological involvement may not be detected due to early mortality, which occurs within 1 or 2 years of life. Studies in animals and autopsy results clearly indicate that lysosomal glycogen does accumulate in the CNS. Thus, latent neurological manifestations may eventually come to light as enzyme replacement therapy prolongs the lives of infantile patients.

Since our group has studied the role of autophagy in PD, more detailed descriptions of methods we have used are included.

Model systems: $\mathrm{GAA}^{-1-}$ mice and myoblasts derived from these mice have been studied (Fukuda et al., 2006b; Raben et al., 1998). In addition, myoblasts and myotubes, as well as muscle biopsies, from patients with Pompe disease were analyzed (Raben et al., 2007).

General techniques: Conventional transmission electron microscopy remains the most reliable technique to visualize autophagic vacuolization in skeletal muscle in Pompe disease as well as in other disorders affecting muscle. One of the intrinsic pitfalls of EM in Pompe disease is that lysosomal glycogen is often lost during processing leaving large empty spaces in the EM images. The following fixation method can be used to preserve lysosomal glycogen for EM (as recommended by Dr. Andrew Engel). We have used this protocol for EM of $\mathrm{GAA}^{-/-}$mice, but it can also be used to analyze human muscle biopsy.

i. The mouse is euthanized, placed on a platform, and dissected to expose muscle. In mice white gastrocnemius, externum digitorum longus (EDL), tibialis anterior (TA) and psoas muscles are a good source of fast-twitch glycolytic type II fibers, whereas soleus muscle is a good source of slow-twitch oxidative type I fibers.

ii. Immediately after dissection, the clamped muscles are injected with ice-cold 5\% glutaraldehyde (Cat. No. 16220; Electron Microscopy Sciences, Hatfield, PA) buffered with $0.1 M$ sodium phosphate, using a 27-gauge hypodermic needle. (A commonly used fixation in 3\% EM grade glutaraldehyde buffered with $0.1 M$ sodium cacodylate buffer results in a significant loss of lysosomal glycogen.) Clamps suitable for mouse muscle can be obtained from Fine Science Tools, Inc. (Cat. No. 00396-01; North Vancouver, British Columbia, Canada). Ice-cold buffered glutaraldehyde can also be injected into the selected muscle in situ so that the muscle is first fixed for at least several minutes in its natural setting.

iii. The clamped muscles are then removed, pinned at rest length (or slightly extended) on a Sylgard-coated plate (preparation of Sylgard-coated plates are described at the end of this protocol), and kept immersed in the same fixative for $2 \mathrm{~h}$. The clamps can be removed once the muscle is pinned.

iv. The muscles are divided into small blocks, rinsed and kept in ice-cold 0.1M sodium phosphate buffer overnight.

v. Small blocks of muscle are then cut, osmicated and dehydrated before Epon embedding according to standard procedures.

To preserve microtubules, room temperature fixative should be used, but some glycogen may be lost. EM reveals the presence of large autophagic areas in predominantly Type II-rich muscle derived from $\mathrm{GAA}^{-/-}$mice (Fukuda et al., 2006b). 
Preparation of Sylgard dissection plates: (Sylgard 182 Silicone Elastomer kit; Robert McKeown Company, Branchburg, NJ, Cat. No. 1821.1):

a. Mix $1 \mathrm{vol}$ of curing agent in $10 \mathrm{vol}$ of silicone elastomer in a plastic disposable container; stir slowly to avoid bubbles.

b. Pour the solution into small tissue culture dishes (Cat. No. 353002; Becton Dickinson Labware, Franklin Lakes, NJ); approximately $5 \mathrm{ml}$ of the solution is needed for one dish.

c. The plates are then allowed to sit un-covered for $48 \mathrm{~h}$ for the Sylgard to polymerize.

d. Note, that if needed (for example, for culturing of live single muscle fibers) the procedure can be done under sterile conditions in a tissue culture hood.

Specific techniques: Autophagy in skeletal muscle can be detected by immunostaining of single fixed muscle fibers. The fixation for immunostaining is quite different from that for EM; the protocol was originally described by Ploug et al. (1998) and Ralston et al. (1999).

1. $2 \%$ paraformaldehyde in $0.1 M$ sodium phosphate buffer:

a. $4 \%$ paraformaldehyde: mix $10 \mathrm{ml}$ of $16 \%$ paraformaldehyde (Cat. No. 15710; Electron Microscopy Sciences, Fort Washington, PA) and $30 \mathrm{ml}$ of $\mathrm{H}_{2} \mathrm{O}$.

b. $\quad 0.2 M$ phosphate buffer, $\mathrm{pH}$ 7.2: $\mathrm{mix} 13.6 \mathrm{ml} 1 M \mathrm{Na}_{2} \mathrm{HPO} 4$ and $6.32 \mathrm{ml} 1$ $M \mathrm{NaH}_{2} \mathrm{PO}$, add $\mathrm{H}_{2} \mathrm{O}$ up to $100 \mathrm{ml}$.

c. Mix equal volumes of $4 \%$ paraformaldehyde and $0.2 M$ phosphate buffer, $\mathrm{pH} 7.2$.

2. Sylgard Silicone Elastomer kit (see above).

3. Methanol (stored at $-20^{\circ} \mathrm{C}$ ).

4. $\mathrm{PBS}(1 \mathrm{X})$.

1. Muscle samples are removed immediately after sacrifice from wild-type and $\mathrm{GAA}^{-/-}$mice, pinned to a Sylgard-coated dish, and submerged in $2 \%$ paraformaldehyde in $0.1 M$ phosphate buffer for $1 \mathrm{~h}$ for fixation at room temperature.

2. Samples are gently blotted using a paper towel, rinsed in PBS, and cleaned of any extraneous material under a dissecting microscope.

3. After cleaning each sample, muscles are blotted again, transferred into tubes containing cold methanol, and placed at $-20^{\circ} \mathrm{C}$ for $6 \mathrm{~min}$. We recommend using a 24-well plate when multiple muscles from several mice are analyzed.

4. Samples are again rinsed with PBS; make sure that the muscle is fully submerged in PBS.

5. Samples may be used immediately or stored. For storage, samples are placed in $50 \%$ glycerol at $4{ }^{\circ} \mathrm{C}$ for 1 day and then moved to $-20^{\circ} \mathrm{C}$. For immediate use, samples are placed in PBS at $4{ }^{\circ} \mathrm{C}$.

The methanol step is important for immunostaining with some antibodies (for example, antialpha-tubulin for staining of the microtubules). However, LAMP and LC3 immunostaining works well on single muscle fibers fixed in paraformaldehyde alone. 
1. $4 \%$ saponin stock solution $(100 \times)$; keep at $-20{ }^{\circ} \mathrm{C}$ in aliquots; once defrosted the solution is stable for approximately 1 week at $4{ }^{\circ} \mathrm{C}$.

2. Sylgard-coated plates.

3. $10 \%$ Triton $\mathrm{X}-100$ in PBS stock solution.

4. Vector M.O.M. Immunodetection Kit (Vector Laboratories, Burlingame, CA). This kit is specifically designed for immunodetection using mouse monoclonal or polyclonal primary antibodies on mouse tissues (including muscle). We routinely use the reagents contained in the kit (blocking buffer and diluent for primary and secondary antibodies) for all immunostaining of single muscle fibers.

5. Hoechst 33342 (Cat. No. H21492; Invitrogen, Carlsbad, CA). The solid dye may be dissolved in PBS to make concentrated stock solutions of $0.1 \mathrm{mg} / \mathrm{ml}$. Stock solutions may be stored frozen, protected from light.

1. Fixed muscle stored at $-20{ }^{\circ} \mathrm{C}$ in a $50 \%$ solution of glycerol in PBS must be gradually transitioned to lesser concentrations of glycerol (first $25 \%$ glycerol then $12 \%$ glycerol for at least $10 \mathrm{~min}$ each). When transitioning and for all other steps, muscle bundles should be held at the ends with tweezers.

2. Muscle bundles are placed in a puddle of $0.04 \%$ saponin in PBS on a Sylgard-coated plate under a dissecting microscope. Fibers are then gently pulled apart from muscle bundles with the finest available tweezers (we use tweezers from Dumont, Switzerland, Cat. No. RS-4905). Make sure the fibers stay wet at all times.

3. Once isolated, fibers are transferred to a well of a 24-well plate (approximately 20 fibers per well) containing blocking solution (prepared according to the manufacturer's instructions). We add $0.2 \%$ Triton X-100 to the blocking solution to make the myofiber membranes more permeable. The effect of Triton X-100 is irreversible, so there is no need to have it in any subsequent solutions. The fibers tend to stick to the tweezers, so be wary of that when placing them in the well.

4. Fibers are incubated in the blocking solution for at least an hour.

5. Under the microscope, the blocking solution is removed from the wells using a 200$\mu \mathrm{L}$ pipette.

6. $500 \mu \mathrm{L}$ of diluent solution (M.O.M. kit) is added immediately.

7. Fibers are incubated at $4{ }^{\circ} \mathrm{C}$ on a shaker overnight with primary antibody in diluent (dilution is antibody-specific). More than one antibody may be used.

8. Fibers are washed twice for $10-15 \mathrm{~min}$ in PBS on a shaker.

9. $\mathrm{PBS}$ is removed and $500 \mu \mathrm{L}$ of diluent are added to each well. Samples are allowed to incubate in secondary antibody and diluent at room temperature for $2 \mathrm{~h}$. The fibers should be protected from light to avoid a loss of fluorescence due to photobleaching.

10. Fibers are washed twice with PBS for $10-15 \mathrm{~min}$. Hoechst staining for nuclei can be added to the first wash to a final concentration of $0.5 \mu \mathrm{g} / \mathrm{ml}$ (a $200 \times$ dilution of the stock).

11. Fibers are mounted on a slide in Vectashield mounting medium (Vector Laboratories, Burlingame, CA; catalog No. H-1000). Using the microscope to view the well, fibers are transferred to a drop of Vectashield on a slide. The slide is placed under the microscope and fibers are dragged out of the drop and lined up next to each other. A coverslip is gently and evenly placed over the fibers and the Vectashield, so that the Vectashield spreads evenly under the cover slip. Excess Vectashield is removed 
(remove as much of the mounting medium as possible) and the cover slip is sealed in place with nail polish.

12. Fibers are analyzed by confocal microscopy.

Immunostaining of muscle fibers isolated from $\mathrm{GAA}^{-1-}$ mice with LAMP-1 (rat anti-mouse LAMP-1; BD Pharmingen, San Diego, CA; Cat. No. 553792) and LC3 (rabbit anti-LC3; Sigma, Cat. No. L7543) antibodies reveals lysosomal enlargement in all fibers and massive autophagic vacuolization in glycolytic fast muscle. The integrity of late endosomal/lysosomal and autophagosomal vesicles in the affected fibers is lost as the disease progresses in older animals. The autophagic buildup appears to disrupt muscle architecture, indicating that the failure of autophagy contributes to the pathology of Pompe disease along with enlargement of glycogenfilled lysosomes (Fukuda et al., 2006a,b; Raben et al., 2007). Functional consequences of the autophagic failure in skeletal muscle can be evaluated by immunostaining of the fibers with antibodies specific for ubiquitin-protein conjugates [mouse monoclonal FK1 (Cat. No. PW8805) and FK2 (Cat. No. PW8810) antibodies; BIOMOL International, L.P., Philadelphia, PA)] as well as for p62/SQSTM1 (mouse monoclonal, Santa Cruz Biotechnology, Inc., Santa Cruz, Cat. No. sc-28359).

\subsection{Defects in Transmembrane Proteins}

3.2.1. Niemann-Pick type C (NPC)—NPC is a fatal early-onset progressive neurodegenerative disorder that mainly affects children. The vast majority of cases are caused by mutations in the NPC1 gene (Carstea et al., 1997), which encodes a membrane-spanning protein that functions in late endosomes to promote lipid sorting and vesicular trafficking. The remaining cases are due to mutations in the NPC2 gene (Naureckiene et al., 2000), which encodes a cholesterol-binding late endosomal lumenal protein. NPC is an example of a disease in which both the accumulation of undegraded compounds (cholesterol and other lipids) and the deficiency of metabolic products normally derived from the stored material, such as oxysterols, play a key role in the pathogenesis (Frolov et al., 2003; Walkley, 2007). The major pathology occurs in liver, spleen, and the CNS.

Model systems: Two spontaneous mouse models of NPC are available: C57BLKS/J spm (Miyawaki et al., 1982) and BALB/c $n p c l^{\text {nih }}$ (Pentchev et al., 1980). Both contain mutations in the NPCl gene and show progressive loss of cerebellar Purkinje cells (PC) and early decline in glia in the corpus callosum (Loftus et al., 1997). Autophagy was studied in a different NPC mouse model, termed aggregation chimeras, which was generated by fusing the embryos of NPC KO mice and transgenic mice with ubiquitous GFP expression. In these chimeric NPC mutant mice, wild-type cells were GFP positive, whereas mutant NPC cells were not. The contribution from wild-type cells ranged from 11-61\%. The ongoing death of mutant NPC cells surrounded by wild-type cells established the cell-autonomous nature of neuronal loss, pointing to the involvement of intracellular pathways, such as autophagy (Ko et al., 2005). Human fibroblasts from patients with the disease have also been used (Pacheco et al., 2007). The importance of choosing an adequate model system was emphasized by studies in NPCdeficient mutant CT60 Chinese hamster ovary cells. Although these cells were capable of responding to autophagic stimuli, they did not faithfully replicate the disease pathology in terms of autophagic abnormalities (Ko et al., 2005).

General techniques: An increase in autophagy in chimeric mice and primary human fibroblasts was shown by ultrastructural detection of autophagic vacuoles, immunoblotting and immunofluorescence analysis of LC3, measurement of protein degradation, and analysis of the mTOR signaling pathway (Bi and Liao 2007; Ko et al., 2005; Pacheco et al., 2007). Numerous inclusion bodies and membranous vacuoles with double-membranes or multilamellar electrondense material were observed in the affected brain by EM (Bi and Liao 2007). The fact 
that LC3-II levels in human fibroblasts are increased by treatment with lysosomal protease inhibitors E64D and pepstatin A indicates that autophagosomal-lysosomal fusion is occurring (Pacheco and Lieberman, 2007; Pacheco et al., 2007). The progression of neuronal degeneration was associated with a dramatic increase in LC3-II levels in brains of chimeric mice (Ko et al., 2005), enhanced protein turnover in NPC fibroblasts, and upregulation of Beclin1 (but no change in activity of Akt, mTOR, or p70 S6K) in mouse tissues and human fibroblasts (Pacheco and Lieberman, 2007; Pacheco et al., 2007). SiRNA down-regulation of Beclin 1 reversed the increased protein turnover in NPC-deficient cells (Pacheco and Lieberman, 2007; Pacheco et al., 2007). LC3-labeled autophagosomes accumulated within filipin-labeled cholesterol clusters inside Purkinje cells (Bi and Liao, 2007).

Specific techniques: Particular aspects of this pathogenetically complex disease are addressed by a number of tailored approaches. These approaches include:

a. Identification of the substrate responsible for autophagic induction by pharmacological means. This is done by exposing the NPC1-deficient cells to $\mathrm{N}$ butyl-deoxygalactonojirimycin (NB-DGJ, Toronto Research Chemicals, Cat. No. B690500), a compound used in substrate deprivation therapy for glycosphingolipid disorders, and by exposing control fibroblasts to the U18666A (Sigma, Cat. No. U3633), a compound known to inhibit cholesterol transport and to induce an accumulation of unesterified cholesterol (reviewed in (Koh and Cheung, 2006)). A decrease in glycosphingolipid level in the NPC1-deficient fibroblasts by treatment with NB-DGJ (Vruchte et al., 2004) did not affect the levels of LC3 or Beclin 1. In contrast, U18666A, increased both LC3 and Beclin 1 in control fibroblasts, indicating that elevated autophagy in NPC cells is a result of altered lipid trafficking and not glycosphingolipid accumulation (Pacheco and Lieberman, 2007; Pacheco et al., 2007).

b. Investigation of the role of Beclin 1 in the induction of autophagy by analyzing a panel of primary fibroblasts derived from patients with several sphingolipid disorders. An increase in Beclin 1 is found in the diseases with abnormal trafficking of sphingolipids (NPC1, NPC2, and Sandhoff disease, a deficiency of both lysosomal hexosaminidase A and B), but not in Gaucher cells, which have proper trafficking (Pacheco and Lieberman, 2007; Pacheco et al., 2007).

c. Analysis of cathepsin D and B levels in NPC1 KO mice. Western blot analysis, immunohistochemistry, and enzymatic assays revealed increased levels of cathepsin $\mathrm{D}$ and B throughout the brains of NPC1 KO mice with the highest increase in the regions that exhibit early and profound neurodegeneration. Immunoblotting of fractionated brain homogenates revealed high levels of ubiquitinated proteins, cathepsin D and rab7 (a protein involved in vesicle maturation) in the late endosomal/ lysosomal fraction (Bi and Liao, 2007; Gutierrez et al., 2004; Jager et al., 2004; Liao et al., 2007).

Thus, unlike other LSDs, NPC is characterized not by a block but rather an induction of autophagy, which is associated with increased levels of Beclin 1 expression.

3.2.2. Neuronal ceroid lipofuscinosis (Batten disease)—Batten disease belongs to a group of neurodegenerative disorders called the neuronal ceroid lipofuscinoses (NCLs), the most common causes of neurodegeneration among children. There are at least seven known genes that, when mutated, cause human NCL, including Cathepsin D (CD) (Mole, 2004; Shacka and Roth 2007; Siintola et al., 2006; Steinfeld et al., 2006). A major pathological hallmark is the accumulation of lipofuscin and ceroid, a lipofuscin-like lipopigment, in the lysosomes of neurons and other cell types. Most of the NCLs result in the lysosomal 
accumulation of subunit $c$ of the mitochondrial ATP synthase, which requires cathepsin D for turnover in the lysosome (Ezaki et al., 2000). Mutations in the CLN3 gene encoding battenin cause juvenile onset NCL (JNCL, Batten disease), which is the most common among NCLs. Battenin is a late endosomal/lysosomal multipass transmembrane protein implicated in membrane trafficking and mitochondrial function. The majority of JNCL patients share a founder mutation: a deletion of exons 7-8 in CLN3. Clinical manifestations include visual failure, seizures, and progressive physical and mental decline associated with massive loss of cortical neurons.

Model systems: Autophagy was studied in cathepsin D knockout and cathepsin B and L double-knockout mice (Koike et al., 2005), which were generated from pre-existing heterozygous lines. The neuronal pathology in mouse brains near the terminal stage (less than one month) is highly reminiscent of NCL pathology: progressive accumulation of undigested lipopigment and proteins including subunit $c$ of mitochondrial ATP synthase in the affected neurons (Koike et al., 2000, 2005). Transgenic GFP-LC3 mice on cathepsin D knockout background were also developed (Koike et al., 2005). A knock-in mouse model (Cln $3^{\mathrm{Aex} 7 / 8}$ mice) has also been generated, which replicates the common JNCL mutation in the murine Cln3 gene (Cotman et al., 2002).

An immortalized cerebellar cell culture model $\left(\mathrm{CbCln} 3^{\Delta \mathrm{ex} 7 / 8}\right.$ cells) has been derived from the $C \ln 3^{\Delta \mathrm{ex} 7 / 8}$ mice (Fossale et al., 2004). These cells express low levels of mutant battenin and can differentiate into MAP-2 and NeuN-positive, neuron-like cells. At sub-confluent growth, the cells exhibit abnormalities in cathepsin $\mathrm{D}$ transport and processing, altered lysosomal size and distribution, abnormally elongated mitochondria, reduced endocytosis, reduction in cellular ATP levels, and decreased survival following oxidative stress. Only when aged at confluency do $\mathrm{CbCln} 3^{\mathrm{Aex} 7 / 8}$ cells accumulate ATP synthase subunit $c$.

General techniques: For analysis of cathepsin-deficient mice (Koike et al., 2005): Immunoblot revealed a gradual age-dependent increase in LC3-II in brain, and immunohistochemistry showed intense granular staining of LC3 in cortical neurons, as well as strong autofluorescence and immunoreactivity for subunit $c$ in neurons and microglia. Double staining with LAMP-1 and LC3 showed some co-localization, but a considerable number of LC3-positive structures were free from LAMP-1, suggesting a defect in autophagosomal maturation. A combination of EM and morphometry was used to evaluate the volume density of autophagosome-like structures, including various types of AVs, dense bodies, granular osmiophilic deposit (GROD)-like inclusions, and fingerprint profiles.

For analysis of knock-in Cln3 $3^{4 e x 7 / 8}$ mice (Cao et al., 2006): Increased autophagy in brains of homozygous $C \ln 3^{\Delta \mathrm{ex} 7 / 8}$ mice, particularly in regions where ATP synthase subunit $c$ accumulates, was shown by immunohistochemistry with anti-LC3 antibody. Western analysis revealed elevated LC3-II/LC3-I ratios in brain from these mice. Reduced levels of phosphomTOR and phospho-p70 S6 kinase were detected in brains of homozygous $C \ln 3^{\Delta \mathrm{ex} 7 / 8}$ mice.

For analysis of CbCln3 ${ }^{4 e x 7 / 8}$ cells (Cao et al., 2006): As in brain, elevated LC3-II/LC3-I ratios and reduced levels of phospho-mTOR and phospho-p70 S6 kinase were detected in the mutant cells. $\mathrm{CbCln} 3^{\Delta \mathrm{ex} 7 / 8}$ cells accumulate subunit $c$ only when grown at confluency (as stated above) or when treated with rapamycin (Cao et al., 2006). 3-MA treatment (5-10 $\mathrm{mM}$ ) resulted in significant cell loss in both wild type and $\mathrm{CbCln} 3^{\Delta \mathrm{ex} 7 / 8}$ cells; the effect was more pronounced in the mutant cells. 3-MA treatment produced similar results in JNCL patient lymphoblasts.

Specific techniques: Several specific methods were used to demonstrate the disruption of autophagy in knock-in $C \ln 3^{\Delta \mathrm{ex} 7 / 8}$ mice and $\mathrm{CbC} \ln 3^{\Delta \mathrm{ex} 7 / 8}$ cells (Cao et al., 2006). 
a. Fractions corresponding to autophagosomes, autophagolysosomes, and lysosomes are isolated from liver of $C \ln 3^{\Delta \mathrm{ex} 7 / 8}$ and wild-type mice (see previously). These fractions are then analyzed by western blotting and transmission EM. These methods reveal that the autophagosomal and lysosomal fractions from $C \ln 3^{\Delta \text { ex7/8 }}$ liver contain a significant amount of undigested material including multilamellar membranes and fingerprint-like storage material, neither of which is seen in control livers. In addition, the recovery of subunit $c$ is significantly enhanced in the light AV fraction and in the lysosomal fraction of $C \ln 3^{\Delta \mathrm{ex} 7 / 8}$ liver. Increases in LC3-II, LAMP1, and cathepsin D are also detected in the light $\mathrm{AV}$ fraction from $C \ln 3^{\Delta \mathrm{ex} 7 / 8}$ liver.

b. A combined endocytic uptake and LysoTracker (labels lysosomes and autolysosomes) staining assay was performed in wild-type and $C \ln 3^{\Delta \text { ex } 7 / 8}$ cells. Two endocytic dyes were used: the lysine-fixable dextran BODIPY FL (Cat. No. D7168) or dextran Alexa Fluor 488 (Cat. No. D22910) (both from Molecular Probes/ Invitrogen). The procedure involves incubation of the cells (seeded at a density of 3$5 \times 10^{4}$ /well in 4-well chamber slides in DMEM medium supplemented with $10 \%$ fetal bovine serum and $24 \mathrm{mM} \mathrm{KCl}$ ) with both LysoTracker and the dextran dye (1 $\mathrm{mg} / \mathrm{ml}$ ) at $33{ }^{\circ} \mathrm{C}$ for $20-50 \mathrm{~min}$. The labeled cells are then placed on ice, washed for $10 \mathrm{~min}$ in ice-cold dye-free medium, fixed in $4 \%$ formaldehyde in PBS for $20 \mathrm{~min}$ on ice, and analyzed by confocal microscopy (Cao et al., 2006; Fossale et al., 2004).

Stimulation of autophagy with rapamycin $(100 \mathrm{n} M, 4 \mathrm{~h})$ in these cells up-regulated both endocytic uptake and LisoTracker stain and promoted their co-localization in both wild-type and $C \ln 3^{\Delta \mathrm{ex} 7 / 8}$ cells, emphasizing the communication between the autophagic and endocytic pathways. Co-localization, however, was much lower in $C \ln 3^{\Delta \text { ex } 7 / 8}$ cells, suggesting impaired trafficking between the endocytic and autophagosomal-lysosomal pathways (Cao et al., 2006).

These experiments led to the proposal of a hypothetical model of the disruption of autophagy in NCL. According to this model, battenin resides on the membranes of late endosomes, lysosomes, and autophagosomes, where it plays a role in autophagosomal maturation and vesicular fusion. Thus, defective battenin would result in nutrient deficiency, up-regulation of autophagy, and accumulation of undegraded substrates, including subunit $c$ of ATP synthase. The upregulation of autophagy, however, is unlikely to rescue the cells, since autophagosomal maturation is profoundly impaired (Cao et al., 2006).

3.2.3. Mucolipidosis (ML): Mucolipidosis type IV (MLIV) belongs to a group of lysosomal storage diseases characterized by accumulation of membranous lipid inclusions in lysosomes (Bach 2001). The disease is caused by mutations in the gene encoding mucolipin 1 (TRP-ML1), a member of the TRP family of ion channels. The pathological hallmark is neuromotor retardation. TRP-ML1 is ubiquitously expressed, and the degenerative processes are not limited to the brain but are also documented in cornea, retina, skeletal muscles, pituitary gland, and other tissues. The exact role of TRP-ML1 is still unclear. The protein is thought to be involved in vesicle fusion in the endocytic pathway, and recently TRP-ML1 was shown to control lysosomal pH (Soyombo et al., 2006).

Model systems: Cultured skin fibroblast from MLIV patients have been used to investigate the mitochondrial-autophagosomal axis in mucolipidoses. Heterozygous (phenotypically normal) fibroblasts from patients' parents served as controls along with MLII and MLIII fibroblasts. In addition to their ready availability, fibroblasts are an attractive model because corneal opacification is a common clinical manifestation of ML, and corneal keratinocytes are similar to fibroblasts in many respects (Jennings, Jr. et al., 2006). MCOLN1 knockout mice have been recently created, which replicate human MLIV. These mice may be used to study autophagy in the future (Venugopal et al., 2007). 
a. Analysis of mitochondrial appearance in MLIV skin fibroblasts. Fibroblasts from a MLIV patient and a heterozygous control were loaded with MitoTracker Red (Cat. No. M-22425) (1 $\mu \mathrm{m})$ or 123-rhodamine (Cat. No. R-22420) $(1 \mu \mathrm{m})$ (both from Molecular Probes/Invitrogen) according to standard procedures. Confocal microscopy revealed mitochondrial fragmentation in MLIV fibroblasts. The significance of this finding is underlined by the fact that the same results were obtained in MLII, MLIII, and NCL2 fibroblasts (Jennings et al., 2006).

b. Pharmacological inhibition of autophagosomal or lysosomal function in control fibroblasts by treatment with bafilomycin (an inhibitor of the lysosomal $\mathrm{H}^{+}$pump), 3-MA, nigericin (an $\mathrm{H}^{+}$ionophore), or ammonium chloride (a lysosome alkalinizing agent). These compounds induce mitochondrial fragmentation in control cells. By extension, this suggests that in ML and perhaps other LSDs, a block in the lysosomal/ autophagosomal pathway leads to accumulation of fragmented mitochondria (Jennings et al., 2006).

c. Measurement of mitochondrial $\mathrm{Ca}^{2+}$ buffering capacity. MLIV and control fibroblasts are treated with bradykinin $(\mathrm{Bk}), \mathrm{a} \mathrm{Ca}^{2+}$-mobilizing agonist, to increase the level of cytoplasmic $\mathrm{Ca}^{2+}$. A fraction of the cytoplasmic $\mathrm{Ca}^{2+}$ is taken up by functional mitochondria. By exposing cells to FCCP (the mitochondrial uncoupler, which collapses mitochondrial membrane potential and causes mitochondria to release $\mathrm{Ca}^{2+}$ ), it is possible to quantify the uptake. Cytoplasmic $\mathrm{Ca}^{2+}$ is then measured by incubation of the cells with Fura-2AM, a dye that undergoes a shift in excitation maximum upon binding calcium (Jennings, Jr. et al., 2006; Soyombo et al., 2006). Unlike in wild-type cells, no $\mathrm{Ca}^{2+}$ release was seen in MLIV or III cells, indicating impaired mitochondrial buffering capacity. Consistent with these data, Rhod2, a fluorescent marker for mitochondrial $\mathrm{Ca}^{2+}$, accumulated in control but not MLIV fibroblasts upon bradykinin treatment. FCCP-mediated $\mathrm{Ca}^{2+}$ release was eliminated by pretreatment of unaffected cells with 3-MA or bafilomycin, suggesting that accumulation of mitochondria with reduced $\mathrm{Ca}^{2+}$ buffering capacity in ML cells is due to defects in the lysosomal/autophagosomal system (Jennings et al., 2006).

d. Analysis of the susceptibility of MLIV fibroblasts to $\mathrm{Ca}^{2+}$-induced apoptosis. Mitochondrial buffering is thought to play a protective role against $\mathrm{Ca}^{2+}$-mediated cytochrome $c$ release and subsequent apoptosis. Treatment of the MLIV and control fibroblasts with bradykinin ( $1 \mu M$ for 1-3 hours) induced apoptosis in a greater fraction of mutant than control cells (Jennings et al., 2006).

Thus, impaired lysosomal function in MLIV affects autophagic degradation of mitochondria, which in turn results in accumulation of abnormal mitochondria with reduced $\mathrm{Ca}^{2+}$ buffering capacity, leaving cells more susceptible to apoptosis.

3.2.4. Danon disease-Danon disease is an X-linked disorder caused by mutations in the gene encoding lysosome-associated membrane protein 2, LAMP-2 (Nishino et al., 2000). The major pathological features of the disease are vacuolar myopathy and cardiomyopathy. Originally the disease was described as a glycogen storage disease similar to Pompe syndrome, but with normal acid alpha-glucosidase activity (Danon et al., 1981). However, it later became clear that not all patients accumulate lysosomal glycogen (Nishino, 2003; Nishino et al., 2000). Severe cardiomyopathy is a feature in all affected patients, while skeletal muscle involvement and mental retardation are seen in most (Yang and Vatta, 2007).

Model systems: LAMP-2 knockout mice replicate some of the major pathological findings in patients with Danon disease, including the accumulation of autophagic vacuoles in cardiac and 
skeletal muscle. In these mice, however, neutrophilic leukocytes, hepatocytes, and acinar gland cells are also affected, which is not the case in patients (Tanaka et al., 2000).

Hepatocytes (Tanaka et al., 2000; Eskelinen et al., 2002) and fibroblasts (Eskelinen et al., 2004) derived from LAMP-2 knockout mice have also been analyzed. In addition, HeLa cells transfected with LAMP-2 siRNA have been studied (Gonzalez-Polo et al., 2005).

General techniques: EM reveals accumulation of autophagic vacuoles in many tissues from LAMP- $2^{-1-}$ mice, including liver, kidney, pancreas, cardiac muscle and skeletal muscle. Cultured LAMP2 $2^{-1-}$ hepatocytes show increased density of early autophagic vacuoles relative to control cells (Tanaka et al., 2000). DAMP labeling of cultured hepatocytes indicated that LAMP-2-deficiency did not affect autophagosomal pH (Tanaka et al., 2000). Western blotting revealed lower levels of mature cathepsin D in LAMP-2 $2^{-/-}$hepatocytes, and metabolic labeling of these cells showed increased secretion of cathepsin D as compared to control cells (Eskelinen et al., 2002). Metabolic labeling also demonstrated lower baseline and starvation-induced proteolysis in LAMP-2-/- hepatocytes as compared to controls (Tanaka et al., 2000). Knocking down LAMP-2 in HeLa cells with siRNA decreased starvation-induced co-localization of GFPLC3 and LysoTracker Red, suggesting a role for LAMP-2 in autophagosomal-lysosomal fusion. $\mathrm{DiOC}_{6}$ staining in these cells revealed a loss of mitochondrial membrane potential after starvation (Gonzalez-Polo et al., 2005).

a. A combination of several traditional methods is used to study the maturation of autophagosomes in LAMP- $2^{-/-}$hepatocytes. Cells are cultured in starvation medium (without serum and amino acids) for $5 \mathrm{~h}$ to induce autophagy, followed by a 1- or 3$\mathrm{h}$ chase in complete medium with 3-MA (which prevents de novo autophagosome formation). Cells are harvested before starvation, after starvation, and after chase and analyzed by EM. In wild-type cells, starvation-induced autophagosomes are mostly resolved after a 3-hour chase. In contrast, in LAMP- $2^{-/-}$cells, autophagosomes persist after a 3-h chase, suggesting a defect in autophagosome maturation and resolution (Eskelinen et al., 2002).

b. Western blotting shows a lower density of cation-dependent mannose-6-phosphate receptor (MPR46, a receptor involved in delivery of endogenous lysosomal enzymes) in LAMP-2-/- hepatocytes (Eskelinen et al., 2002). Radiolabeling and immunoprecipitation of MPR46 in these cells shows that the receptor has a decreased half-life, which could be restored by inhibition of lysosomal proteases. Immunogold EM of LAMP- $2^{-1-}$ hepatocytes revealed increased amounts of MPR46 within autophagosomes and loss of MPR46 from multivesicular endosomes, which are involved in receptor recycling. Thus, aberrant targeting of MPR46 to the autophagosomal/lysosomal pathway may lead to down-regulation of the receptor in LAMP- $2^{-1-}$ cells (Eskelinen et al., 2002).

c. HeLa cells are transfected with LAMP-2 siRNA, mt-dsRed (a mitochondrial marker), and SytVII-GFP (a lysosomal marker). Confocal microscopy of cells reveals decreased co-localization of mitochondrial and lysosomal markers in LAMP-2deficient cells, indicating decreased mitochondrial turnover (Gonzalez-Polo et al., 2005).

Thus, the role of LAMP-2, previously thought to be limited to protecting the cytoplasm from the contents of the lysosome, is now seen to include lysosomal biogenesis and the late steps of the autophagic pathway (Eskelinen et al., 2004). 


\section{Conclusion}

Lysosomal storage disorders are not new nosologic entities; they were described decades, and in some cases even a century ago. The discovery of the lysosome and the connection between a particular enzyme deficiency and a corresponding storage material came much later in the mid to late part of the last century. These discoveries paved the way for the identification of the genes involved and the mutations found in patients. Exploration of the primary defects of these diseases and the development of enzyme replacement therapy for some of these disorders followed. The new chapter in LSDs is marked by extending research beyond the lysosome and focusing on the secondary events following lysosomal dysfunction. Autophagy is clearly one of the interrelated pathways affected. One consequence of autophagic abnormalities is the impaired degradation of mitochondria. The similar range of pathological manifestations in many LSDs, in particular those with neurological involvement, suggested that a generalized mechanism of degeneration may exist. Autophagy, indeed, appears to be a common factor in these diseases, although the mechanisms by which it contributes to pathology and pathogenesis are variable. The study of autophagy may yet lead to the elucidation of the mechanisms of cellular death and the development of new tailored therapies for these devastating disorders.

\section{References}

Anderson RG, Orci L. A view of acidic intracellular compartments. J Cell Biol 1988;106:539-543. [PubMed: 3279044]

Bach G. Mucolipidosis type IV. Mol Genet Metab 2001;73:197-203. [PubMed: 11461186]

Bhattacharyya R, Gliddon B, Beccari T, Hopwood JJ, Stanley P. A novel missense mutation in lysosomal sulfamidase is the basis of MPS III A in a spontaneous mouse mutant. Glycobiology 2001;11:99-103. [PubMed: 11181566]

Bhaumik M, Muller VJ, Rozaklis T, Johnson L, Dobrenis K, Bhattacharyya R, Wurzelmann S, Finamore P, Hopwood JJ, Walkley SU, Stanley P. A mouse model for mharidosis type III A (Sanfilippo syndrome). Glycobiology 1999;9:1389-1396. [PubMed: 10561464]

Bi X, Liao G. Autophagic-lysosomal dysfunction and neurodegeneration in Niemann-Pick Type C mice: Lipid starvation or indigestion? Autophagy 2007;3:646-648. [PubMed: 17921694]

Cao Y, Espinola JA, Fossale E, Massey AC, Cuervo AM, Macdonald ME, Cotman SL. Autophagy is disrupted in a knock-in mouse model of juvenile neuronal ceroid lipofuscinosis. J Biol Chem 2006;29:20483-20493. [PubMed: 16714284]

Carstea ED, Morris JA, Coleman KG, Loftus SK, Zhang D, Cummings C, Gu J, Rosenfeld MA, Pavon WJ, Krman DB, et al. Niemann-Pick C1 disease gene: Homology to mediators of cholesterol homeostasis. Science 1997;277:228-231. [PubMed: 9211849]

Corcelle E, Nebout M, Bekri S, Gauthier N, Hofman P, Poujeol P, Fenichel P, Mograbi B. Disruption of autophagy at the maturation step by the carcinogen lindane is associated with the sustained mitogenactivated protein kinase/extracellular signal-regulated kinase activity. Cancer Res 2006;66:68616870. [PubMed: 16818664]

Cosma MP, Pepe S, Annunziata I, Newbold RF, Grompe M, Parenti G, Ballabio A. The multiple sulfatase deficiency gene encodes an essential and limiting factor for the activity of sulfatases. Cell 2003;113:445-456. [PubMed: 12757706]

Cotman SL, Vrbanac V, Lebel LA, Lee RL, Johnson RL, Donahue LR, Teed AM, Antonellis K, Bronson RT, Lerner TJ, Macdonald ME. Cln3 (Delta ex7/8) knock-in mice with the common JNCL mutation exhibit progressive neurologic disease that begins before birth. Hum Mol Genet 2002;11:2709-2721. [PubMed: 12374761]

Danon MJ, Oh SJ, DiMauro S, Manaligod JR, Eastwood A, Naidu S, Schliselfeld LH. Lysosomal glycogen storage disease with normal acid maltase. Neurology 1981;31:51-57. [PubMed: 6450334]

de Araujo, MEG.; Huber, LA.; Stasyk, T. Isolation of endocitic organelles by density gradient centrifugation. In: Posch, A., editor. 2D PAGE: Sample Preparation and Fractionation. Humana Press; Totowa, NJ: 2006. p. 317-331. 
Dierks T, Schmidt B, Borissenko LV, Peng J, Preusser A, Mariappan M, von Figura K. Multiple sulfatase deficiency is caused by mutations in the gene encoding the human $\mathrm{C}$ (alpha)-formylglycine generating enzyme. Cell 2003;113:435-444. [PubMed: 12757705]

Elleder M, Sokolova J, Hrebicek M. Follow-up study of subunit c of mitochondrial ATP synthase (SCMAS) in Batten disease and in unrelated lysosomal disorders. Acta Neuropathol 1997;93:379390. [PubMed: 9113203]

Eskelinen EL, Illert AL, Tanaka Y, Schwarzmann G, Blanz J, von Figura K, Saftig P. Role of LAMP-2 in lysosome biogenesis and autophagy. Mol Biol Cell 2002;13:3355-3368. [PubMed: 12221139]

Eskelinen EL, Schmidt CK, Neu S, Willenborg M, Fuertes G, Salvador N, Tanaka Y, Lullmann-Rauch R, Hartmann D, Heeren J, von Figura K, Knecht E, et al. Disturbed cholesterol traffic but normal proteolytic function in LAMP-1/LAMP-2 double-deficient fibroblasts. Mol Biol Cell 2004;15:31323145. [PubMed: 15121881]

Ezaki J, Takeda-Ezaki M, Kominami E. Tripeptidyl peptidase I, the late infantile neuronal ceroid lipofuscinosis gene product, initiates the lysosomal degradation of subunit c of ATP synthase. J Biochem 2000;128:509-516. [PubMed: 10965052]

Fossale E, Wolf P, Espinola JA, Lubicz-Nawrocka T, Teed AM, Gao H, Rigamonti D, Cattaneo E, Macdonald ME, Cotman SL. Membrane trafficking and mitochondrial abnormalities precede subunit c deposition in a cerebellar cell model of juvenile neuronal ceroid lipofuscinosis. BMC Neurosci 2004;5:57. [PubMed: 15588329]

Frolov A, Zielinski SE, Crowley JR, Dudley-Rucker N, Schaffer JE, Ory DS. NPC1 and NPC2 regulate cellular cholesterol homeostasis through generation of low density lipoprotein cholesterol-derived oxysterols. J Biol Chem 2003;278:25517-25525. [PubMed: 12719428]

Fukuda T, Ahearn M, Roberts A, Mattaliano RJ, Zaal K, Ralston E, Plotz PH, Raben N. Autophagy and mistargeting of therapeutic enzyme in skeletal muscle in pompe disease. Mol Ther 2006a;14:831839. [PubMed: 17008131]

Fukuda T, Ewan L, Bauer M, Mattaliano RJ, Zaal K, Ralston E, Plotz PH, Raben N. Dysfunction of endocytic and autophagic pathways in a lysosomal storage disease. Ann Neurol 2006b;59:700-708. [PubMed: 16532490]

Gonzalez-Polo RA, Boya P, Pauleau AL, Jalil A, Larochette N, Souquere S, Eskelinen EL, Pierron G, Saftig P, Kroemer G. The apoptosis/autophagy paradox: Autophagic vacuolization before apoptotic death. Journal of Cell Science 2005;118:3091-3102. [PubMed: 15985464]

Gutierrez MG, Munafo DB, Beron W, Colombo MI. Rab7 is required for the normal progression of the autophagic pathway in mammalian cells. J Cell Sci 2004;117:2687-2697. [PubMed: 15138286]

Hara T, Nakamura K, Matsui M, Yamamoto A, Nakahara Y, Suzuki-Migishima R, Yoyama M, Mishima K, Saito I, Okano H, Mizushima N. Suppression of basal autophagy in neural cells causes neurodegenerative disease in mice. Nature 2006;441:885-889. [PubMed: 16625204]

Hodges BL, Cheng SH. Cell and gene-based therapies for the lysosomal storage diseases. Curr Gene Ther 2006;6:227-241. [PubMed: 16611044]

Hopwood, JJ.; Ballabio, A. Multiple Sulfatase Deficiency and the Nature of the Sulfatase family. Scriver, C.; Beaudet, A.; Valle, D.; Sly, W., editors. McGraw-Hill; New York: 2001. p. 3725-3732.

Itoh M, Matsuda J, Suzuki O, Ogura A, Oshima A, Tai T, Suzuki Y, Takashima S. Development of lysosomal storage in mice with targeted dis ruption of the beta-galactosidase gene: A model of human G(M1)-gangliosidosis. Brain Dev 2001;23:379-384. [PubMed: 11578847]

Jager S, Bucci C, Tanida I, Ueno T, Kominami E, Saftig P, Eskelinen EL. Role for Rab7 in maturation of late autophagic vacuoles. J Cell Sci 2004;117:4837-4848. [PubMed: 15340014]

Jennings JJ Jr, Zhu JH, Rbaibi Y, Luo X, Chu CT, Kiselyov K. Mitochondrial aberrations in mucolipidosis Type IV. J Biol Chem 2006;281:39041-39050. [PubMed: 17056595]

Kabeya Y, Mizushima N, Ueno T, Yamamoto A, Kirisako T, Noda T, Kominami E, Ohsumi Y, Yoshimori T. LC3, a mammalian homologue of yeast Apg8p, is localized in autophagosome membranes after processing. EMBO J 2000;19:5720-5728. [PubMed: 11060023]

Kiselyov K, Jennigs JJ Jr, Rbaibi Y, Chu CT. Autophagy, mitochondria and cell death in lysosomal storage diseases. Autophagy 2007;3:259-262. [PubMed: 17329960]

Klionsky DJ, et al. Guidelines for the use and interpretation of assays for monitoring autophagy in higher eukaryotes. Autophagy 2008;4:151-175. [PubMed: 18188003] 
Ko DC, Milenkovic L, Beier SM, Manuel H, Buchanan J, Scott MP. Cell-autonomous death of cerebellar purkinje neurons with autophagy in Niemann-Pick type C disease. PLoS Genet 2005;1:81-95. [PubMed: 16103921]

Koh CH, Cheung NS. Cellular mechanism of U18666A-mediated apoptosis in cultured murine cortical neurons: Bridging Niemann-Pick disease type C and Alzheimer's disease. Cell Signal 2006;18:18441853. [PubMed: 16797161]

Koike M, Nakanishi H, Saftig P, Ezaki J, Isahara K, Ohsawa Y, Schulz-Schaeffer W, Watanabe T, Waguri S, Kametaka S, Shibata M, Yamamoto K, et al. Cathepsin D deficiency induces lysosomal storage with ceroid lipofuscin in mouse CNS neurons. J Neurosci 2000;20:6898-6906. [PubMed: 10995834]

Koike M, Shibata M, Waguri S, Yoshimura K, Tanida I, Kominami E, Gotow T, Peters C, von Figura K, Mizushima N, Saftig P, Uchiyama Y. Participation of autophagy in storage of lysosomes in neurons from mouse models of neuronal ceroid-lipofuscinoses (Batten disease). Am J Pathol 2005;167:1713-1728. [PubMed: 16314482]

Komatsu M, Waguri S, Chiba T, Murata S, Iwata J, Tanida I, Ueno T, Koike M, Uchiyama Y, Kominami E, Tanaka K. Loss of autophagy in the central nervous system causes neurodegeneration in mice. Nature 2006;441:880-884. [PubMed: 16625205]

Komatsu M, Waguri S, Ueno T, Iwata J, Murata S, Tanida I, Ezaki J, Mizushima N, Ohsumi Y, Uchiyama Y, Kominami E, Tanaka K, et al. Impairment of starvation-induced and constitutive autophagy in Atg7-deficient mice. J Cell Biol 2005;169:425-434. [PubMed: 15866887]

Kramar EA, Lin B, Lin CY, Arai AC, Gall CM, Lynch G. A novel mechanism for the facilitation of thetainduced long-term potentiation by brain-derived neurotrophic factor. J Neurosci 2004;24:5151-5161. [PubMed: 15175384]

Liao G, Yao Y, Liu J, Yu Z, Cheung S, Xie A, Liang X, Bi X. Cholesterol accumulation is associated with lysosomal dysfunction and autophagic stress in Npc1 -/- mouse brain. Am J Pathol 2007;171:962-975. [PubMed: 17631520]

Loftus SK, Morris JA, Carstea ED, Gu JZ, Cummings C, Brown A, Ellison J, Ohno K, Rosenfeld MA, Tagle DA, Pentchev PG, Pavan WJ. Murine model of Niemann-Pick C disease: Mutation in a cholesterol homeostasis gene. Science 1997;277:232-235. [PubMed: 9211850]

Lum JJ, DeBerardinis RJ, Thompson CB. Autophagy in metazoans: Cell survival in the land of plenty. Nat Rev Mol Cell Biol 2005;6:439-448. [PubMed: 15928708]

Marzella L, Ahlberg J, Glaumann H. Isolation of autophagic vacuoles from rat liver: Morphological and biochemical characterization. J Cell Biol 1982;93:144-154. [PubMed: 7068752]

Matsuda J, Suzuki O, Oshima A, Ogura A, Noguchi Y, Yamamoto Y, Asano T, Takimoto K, Sukegawa K, Suzuki Y, Naiki M. Beta-galactosidase-deficient mouse as an animal model for GM1gangliosidosis. Glycoconj J 1997;14:729-736. [PubMed: 9337086]

Maxfield FR. Measurement of vacuolar $\mathrm{pH}$ and cytoplasmic calcium in living cells using fluorescence microscopy. Methods Enzymol 1989;173:745-771. [PubMed: 2779443]

Miyawaki S, Mitsuoka S, Sakiyama T, Kitagawa T. Sphingomyelinosis, a new mutation in the mouse: A model of Niemann-Pick disease in humans. J Hered 1982;73:257-263. [PubMed: 7202025]

Mole SE. The genetic spectrum of human neuronal ceroid-lipofuscinoses. Brain Pathol 2004;14:70-76. [PubMed: 14997939]

Naureckiene S, Sleat DE, Lackland H, Fensom A, Vanier MT, Wattiaux R, Jadot M, Lobel P. Identification of HE1 as the second gene of Niemann-Pick C disease. Science 2000;290:2298-2301. [PubMed: 11125141]

Nishino I. Autophagic vacuolar myopathies. Curr Neurol Neurosci Rep 2003;3:64-69. [PubMed: 12507414]

Nishino I, Fu J, Tanji K, Yamada T, Shimojo S, Koori T, Mora M, Riggs JE, Oh SJ, Koga Y, et al. Primary LAMP-2 deficiency causes X-linked vacuolar cardiomyopathy and myopathy (Danon disease). Nature 2000;406:906-910. [PubMed: 10972294]

Pacheco CD, Kunkel R, Lieberman AP. Autophagy in Niemann-Pick C disease is dependent upon Beclin-1 and responsive to lipid trafficking defects. Hum Mol Genet 2007;16:1495-1503. [PubMed: 17468177]

Pacheco CD, Lieberman AP. Lipid trafficking defects increase Beclin-1 and activate autophagy in Niemann-Pick type C disease. Autophagy 2007;3:487-489. [PubMed: 17611388] 
Pankiv S, Clausen TH, Lamark T, Brech A, Bruun JA, Outzen H, Overvatn A, Bjorkoy G, Johansen T. p62/SQSTM1 binds directly to Atg8/LC3 to facilitate degradation of ubiquitinated protein aggregates by autophagy. J Biol Chem 2007;282:24131-24145. [PubMed: 17580304]

Pentchev PG, Gal AE, Booth AD, Omodeo-Sale F, Fouks J, Neumeyer BA, Quirk JM, Dawson G, Brady RO. A lysosomal storage disorder in mice characterized by a dual deficiency of sphingomyelinase and glucocerebrosidase. Biochim Biophys Acta 1980;619:669-679. [PubMed: 6257302]

Ploug T, van Deurs B, Ai H, Cushman SW, Ralston E. Analysis of GLUT4 distribution in whole skeletal muscle fibers: Identification of distinct storage compartments that are recruited by insulin and muscle contractions. J Cell Biol 1998;142:1429-1446. [PubMed: 9744875]

Poot M, Zhang YZ, Kramer JA, Wells KS, Jones LJ, Hanzel DK, Lugade AG, Singer VL, Haugland RP. Analysis of mitochondrial morphology and function with novel fixable fluorescent stains. $\mathbf{J}$ Histochem Cytochem 1996;44:1363-1372. [PubMed: 8985128]

Raben N, Danon M, Gilbert AL, Dwivedi S, Collins B, Thurberg BL, Mattaliano RJ, Nagaraju K, Plotz PH. Enzyme replacement therapy in the mouse model of Pompe disease. Mol Genet Metab 2003;80:159-169. [PubMed: 14567965]

Raben N, Nagaraju K, Lee E, Kessler P, Byrne B, Lee L, LaMarca M, King C, Ward J, Sauer B, Plotz $\mathrm{P}$. Targeted disruption of the acid alpha-glucosidase gene in mice causes an illness with critical features of both infantile and adult human glycogen storage disease type II. J Biol Chem 1998;273:19086-19092. [PubMed: 9668092]

Raben N, Takikita S, Pittis MG, Bembi B, Marie S, K N, Roberts A, Page L, Kishnani PS, Schoser B, G H, Chien YH, Ralston E, Nagaraju K, et al. Deconstructing Pompe disease by analyzing single muscle fibers. Autophagy 2007;3:546-552. [PubMed: 17592248]

Ralston E, Lu Z, Ploug T. The organization of the Golgi complex and microtubules in skeletal muscle is fiber type-dependent. J Neurosci 1999;19:10694-10705. [PubMed: 10594053]

Settembre C, Annunziata I, Spampanato C, Zarcone D, Cobellis G, Nusco E, Zito E, Tacchetti C, Cosma MP, Ballabio A. Systemic inflammation and neurodegeneration in a mouse model of multiple sulfatase deficiency. Proc Natl Acad Sci USA 2007;104:4506-4511. [PubMed: 17360554]

Settembre C, Fraldi A, Jahreiss L, Spampanato C, Venturi C, Medina D, de Pablo R, Tacchetti C, Rubinsztein DC, Ballabio A. A block of autophagy in lysosomal storage disorders. Hum Mol Genet 2008a;17:119-129. [PubMed: 17913701]

Settembre C, Fraldi A, Rubinsztein DC, Ballabio A. Lysosomal storage diseases as disorders of autophagy. Autophagy 2008b;4:113-114. [PubMed: 18000397]

Shacka JJ, Roth KA. Cathepsin D deficiency and NCL/Batten disease: There's more to death than apoptosis. Autophagy 2007;3:474-476. [PubMed: 17495518]

Siintola E, Partanen S, Stromme P, Haapanen A, Haltia M, Maehlen J, Lehesjoki AE, Tyynela J. Cathepsin D deficiency underlies congenital human neuronal ceroid-lipofuscinosis. Brain 2006;129:14381445. [PubMed: 16670177]

Soyombo AA, Tjon-Kon-Sang S, Rbaibi Y, Bashllari E, Bisceglia J, Muallem S, Kiselyov K. TRP-ML1 regulates lysosomal $\mathrm{pH}$ and acidic lysosomal lipid hydrolytic activity. J Biol Chem 2006;281:72947301. [PubMed: 16361256]

Steinfeld R, Reinhardt K, Schreiber K, Hillebrand M, Kraetzner R, Bruck W, Saftig P, Gartner J. Cathepsin D deficiency is associated with a human neurodegenerative disorder. Am J Hum Genet 2006;78:988-998. [PubMed: 16685649]

Takamura A, Higaki K, Kajimaki K, Otsuka S, Ninomiya H, Matsuda J, Ohno K, Suzuki Y, Nanba E. Enhanced autophagy and mitochondrial aberrations in murine G(M1)-gangliosidosis. Biochem Biophys Res Commun. 2008

Tanaka Y, Guhde G, Suter A, Eskelinen EL, Hartmann D, Lullmann-Rauch R, Janssen P, M L, Blanz J, von Figura K, Saftig P. Accumulation of autophagic vacuoles and cardiomyopathy in LAMP-2deficient mice. Nature 2000;406:902-906. [PubMed: 10972293]

Tassa A, Roux MP, Attaix D, Bechet DM. Class III phosphoinositide 3-kinase-Beclin1 complex mediates the amino acid-dependent regulation of autophagy in C2C12 myotubes. Biochem J 2003;376:577586. [PubMed: 12967324]

Terman A, Brunk UT. Oxidative stress, accumulation of biologicasl "garbage", and aging. Antioxid Redox Signal 2006;8:197-204. [PubMed: 16487053] 
Venugopal B, Browning MF, Curcio-Morelli C, Varro A, Michaud N, Nanthakumar N, Walkley SU, Pickel J, Slaugenhaupt SA. Neurologic, gastric, and opthalmologic pathologies in a murine model of mucolipidosis type IV. Am J Hum Genet 2007;81:1070-1083. [PubMed: 17924347]

Vruchte D, Lloyd-Evans E, Veldman RJ, Neville DC, Dwek RA, Platt FM, van Blitterswijk WJ, Sillence DJ. Accumulation of glycosphingolipids in Niemann-Pick C disease disrupts endosomal transport. J Biol Chem 2004;279:26167-26175. [PubMed: 15078881]

Walkley SU. Pathogenic mechanisms in lysosomal disease: A reappraisal of the role of the lysosome. Acta Paediatr Suppl 2007;96:26-32. [PubMed: 17391436]

Wenger DA, Coppola S, Liu SL. Insights into the diagnosis and treatment of lysosomal storage diseases. Arch Neurol 2003;60:322-328. [PubMed: 12633142]

Xie Z, Klionsky DJ. Autophagosome formation: Core machinery and adaptations. Nat Cell Biol 2007;9:1102-1109. [PubMed: 17909521]

Yang Z, Vatta M. Danon disease as a cause of autophagic vacuolar myopathy. Congenit Heart Dis 2007;2:404-409. [PubMed: 18377432]

Yu WH, Cuervo AM, Kumar A, Peterhoff CM, Schmidt SD, Lee JH, Mohan PS, Mercken M, Farmery MR, Tjernberg LO, Jiang Y, Duff K, et al. Macroautophagy: A novel -amyloid peptide-generating pathway activated in Alzheimer's disease. J Cell Biol 2005;171:87-98. [PubMed: 16203860] 